CIUDAD Y TERRITORIO

ESTUDIOS TERRITORIALES

ISSN(P): 2697-231X; ISSN(E): 2697-2328

Vol. LIII, N.ำ Monográfico 2021

Págs. 159-178

https://doi.org/10.37230/CyTET.2021.M21.09

CC BY-NC-ND

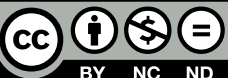

\title{
La Estrategia Regional Andaluza para la Cohesión e Inclusión Social. Intervención en Zonas Desfavorecidas (ERACIS)
}

\author{
Ana Díez-Bermejo(1) \\ Iván RodRígUEZ-SUÁREZ ${ }^{(2)}$ \\ Lucas ÁlVAREZ-DEL VALLE ${ }^{(3)}$ \\ Rafael CóRdobA-HeRNÁNDEZ ${ }^{(4)}$ \\ Gonzalo SÁnCHEZ-TOSCANO ${ }^{(5)}$ \\ Agustín Hernández-Aja ${ }^{(6)}$
}

(1)Arquitecta. Investigadora

(2)Arquitecto. Profesor asociado e investigador

(3)Arquitecto. Investigador

(4)Arquitecto. Profesor asociado e investigador

${ }^{(5)}$ Arquitecto. Investigador

(6)Dr. Arquitecto. Catedrático

Todos ellos del Departamento de Urbanística y Ordenación del Territorio Universidad Politécnica de Madrid

RESUMEN: La Estrategia Regional Andaluza para la Cohesión e Inclusión Social. Intervención en Zonas Desfavorecidas (ERACIS) es una iniciativa puesta en marcha en el año 2018 cuya finalidad es la detección de dichas zonas del territorio andaluz a partir de indicadores y la intervención en ellas a través de Planes Locales de Intervención en Zonas Desfavorecidas (PLIZD) diseñados e implementados por entidades locales. La Estrategia es una política pública integral basada en sistemas de gobernanza multinivel y representa la última generación de instrumentos desarrollados en Andalucía en las tres últimas décadas para

Recibido: 19.10.2020; Revisado: 27.10.2020

Correo electrónico: ana.diez@upm.es; N. ORCID: https://orcid.org/0000-0001-8524-75

Correo electrónico: ivan.rsuarez@upm.es; N ORCID: https://orcid.org/0000-0002-9139-0280

Correo electrónico: lucas.alvarez@upm.es; N. ${ }^{\circ}$ ORCID: https://orcid.org/0000-0003-4956-4547

Correo electrónico: rafael.cordoba@upm.es; N. ${ }^{\circ}$ ORCID: https://orcid.org/0000-0001-7878-2055

Correo electrónico: gonzalo.sancheztoscano@upm.es; N. ${ }^{\circ}$ ORCID: https://orcid.org/0000-0002-4485-058X

Correo electrónico: agustin.hernandez@upm.es; N. ORCID: https://orcid.org/0000-0002-4485-058X

Los autores agradecen los comentarios y sugerencias realizados por los evaluadores anónimos, que han contribuido a mejorar y enriquecer el manuscrito original. 


\title{
The Regional Strategy for Social Cohesion and Inclusion in Andalusia: The "ERACIS" (Estrategia Regional Andaluza para la Cohesión e Inclusión Social. Intervención en Zonas Desfavorecidas)
}

\begin{abstract}
The Estrategia Regional Andaluza para la Cohesión e Inclusión Social. Intervención en Zonas Desfavorecidas (ERACIS) is an initiative launched in 2018 whose goal is to detect Andalucia's disadvantaged areas based on indicators and to intervene them through Local Plans (Planes Locales de Intervención en Zonas Desfavorecidas: PLIZD) designed and implemented by local authorities. This strategy is a comprehensive public policy based on multilevel governance systems and represents the latest generation of instruments developed in Andalucía over three decades to propose specific solutions to public problems in the fight against urban inequality. The article analyzes the objectives, methodologies and implementation of the tool and carries out an evaluation of the urban vulnerability dimensions contemplated in the strategy indicators.
\end{abstract}

KEYWORDS: Deprived areas; Urban vulnerability; Social inclusion; Urban regeneration.

\section{Introducción}

\subsection{Acerca de la herramienta}

a Estrategia Regional Andaluza para la Cohesión e Inclusión Social. Intervención en Zonas Desfavorecidas (ERACIS), es una iniciativa puesta en marcha en el año 2018 por Acuerdo del Consejo de Gobierno (JUNTA DE ANDAlucía, 2018a) a propuesta de la Consejería de Igualdad y Políticas Sociales de la Junta de Andalucía, en cofinanciación con el Programa Operativo FSE de la Comunidad Autónoma de Andalucía 2014-2020 del Fondo Social Europeo.

El cometido de la Estrategia es "la mejora de la calidad de vida de las personas que viven en zonas desfavorecidas a través del diseño, organización y evaluación de la política y gestión pública autonómica y local con la participación de la ciudadanía, diferentes administraciones y entidades públicas y privadas implicadas en la zona" mediante la intervención en estas zonas a través de planes locales de intervención en barrios (Planes Locales de Intervención en Zonas Desfavorecidas, PLIZD) que son diseñados, implementados y coordinados desde las administraciones locales y ejecutados con un enfoque integral y comunitario de forma participada.

La OCDE (OCDE, 1998) definió zona desfavorecida como aquellas áreas donde se concentran problemas sociales, económicos y/o medioambientales. Estos problemas afectan a sus residentes y empresas locales en distintos grados, limitando el acceso a oportunidades, recursos y servicios que se consideran normales en otras partes de la ciudad. La Estrategia recoge el concepto de zona desfavorecida, desde el punto de vista de Arias (ARIAS, 2000), el cual define ésta como aquella que presenta diferentes debilidades en su estructura sociodemográfica y/o en las cualidades ambientales de su espacio físico y que por lo tanto la diferencia del resto de la ciudad, creando desigualdad desde el punto de vista de la calidad de vida. Sin embargo, en este sentido, la Estrategia recoge igualmente el espíritu de la Unión Europea (UNIÓN EUROPEA, 2007), que mira a las áreas urbanas desfavorecidas no como un problema, sino como fuente de capital humano y físico desaprovechado y cuyo potencial tiene que ser desbloqueado para que pueda contribuir al progreso cívico y desarrollo económico general de la ciudad.

Atendiendo a la finalidad que expone, podemos vislumbrar la intención explícita e implícita de convertirse en una política pública de calado, en el sentido de proponer soluciones específicas a problemas públicos, de lucha contra la desigualdad urbana donde refleja todas las dimensiones que una política pública debiera tener (SUBIRATS, 1993): la definición del problema, la participación de actores, la causa a través de la cual toma la decisión de hacer frente al problema, 
los instrumentos y medidas para afrontar los problemas, el sistema de implementación y la presencia de una herramienta de evaluación de la estrategia. La intención de la Estrategia muestra claramente un sentido cooperativo e integral a la hora de afrontar los problemas de desigualdad urbana y cohesión territorial y representa una apuesta por la creación de una estructura territorial con capacidad de intervención y gestión a nivel autonómico reflejada en la dimensión local del territorio.

La ERACIS se ha construido a partir de cuatro ejes, inspirados en la Ley de Servicios Sociales de Andalucía (JUNTA DE ANDALUcía, 2016): desarrollo económico y comunitario sostenible; políticas públicas para el bienestar y la cohesión social; mejora del hábitat y convivencia; trabajo en red e innovación en la intervención social comunitaria. Esta declaración de principios tiene un carácter multidimensional y holístico en lo que al diseño y la implementación de la Estrategia se refiere, que nos recuerda al triángulo sobre el concepto de calidad de vida (grado óptimo de la satisfacción de necesidades) de Alguacil (AlguACIL, 2000): la calidad ambiental (territorio, barrio, vivienda), el bienestar (empleo, educación y empleo) y la identidad cultural (identidades y participación) en sus tres dimensiones, la física, la social y la emocional.

La Estrategia es una herramienta tanto de detección como de intervención en el campo de la vulnerabilidad urbana, es decir, contiene una metodología, con una serie de indicadores, a través de la cual detecta las zonas desfavorecidas del territorio andaluz y a su vez propone como herramienta de intervención, los Planes Locales de Intervención en Zonas Desfavorecidas (PLIZD). El documento en el que se formaliza la Estrategia se estructura, a lo largo de casi ciento cincuenta páginas, en los siguientes epígrafes: una presentación e introducción, un diagnóstico y mapa de zonas desfavorecidas, la misión y los objetivos de la Estrategia, qué tipos de medidas se deben articular para su implementación, la metodología de intervención y, por último, una metodología de seguimiento y evaluación de la propia herramienta.

\subsection{La ERACIS como objeto de estudio}

La elección de esta Estrategia como objeto de estudio responde al objetivo de describir y difundir una herramienta que sintetiza la experiencia histórica en la región de identificación, delimitación e intervención en zonas desfavorecidas y que da un paso hacia la perfección del instrumento, que apenas ha tenido repercusión en los medios académicos, puesto que lleva dos años de implementación, y que resulta de interés por la combinación de la planificación de un territorio en su dimensión estratégica a escala regional y la planificación de éste en una dimensión operativa a través de la escala local, coordinadas ambas administraciones con un objetivo claro: la reducción de la pobreza y el fomento de la inclusión y cohesión social con un enfoque integral de políticas públicas (servicios sociales, educación, salud, vivienda y urbanismo). Desde la Junta de Andalucía, es la Consejería de Igualdad y Políticas Sociales (FIG. 1) la promotora de este instrumento innovador que apuesta por la cohesión social, con el objetivo de incidir tanto en el diseño de las políticas públicas como en su implementación y evaluación, donde destaca la participación activa de todos los agentes implicados: ciudadanos, administraciones públicas, tercer sector y tejido empresarial.

\begin{tabular}{ll}
\hline Nombre & $\begin{array}{l}\text { Estrategia Regional Andaluza para la Cohesión e Inclusión Social. Intervención en Zonas } \\
\text { Desfavorecidas (ERACIS) }\end{array}$ \\
\hline Fecha & 2018 \\
\hline Localización & Comunidad Autónoma de Andalucía \\
\hline Legislación & Acuerdo de 28 de agosto de 2018 del Consejo de Gobierno de la Junta de Andalucía \\
\hline Alcance & Regional \\
\hline Escala de análisis & Municipal e inframunicipal; Unidad mínima de análisis: sección censal \\
\hline Función & Detección e Intervención en zonas desfavorecidas \\
\hline Agente promotor & Consejería de Igualdad, Políticas Sociales y Conciliación \\
\hline URL & https://www.juntadeandalucia.es/organismos/igualdadpoliticassocialesyconciliacion/areas/ \\
\hline
\end{tabular}

FIG. 1/ Cuadro de descripción básica de la ERACIS.

Fuente: elaboración propia en base a la Estrategia Regional Andaluza para la Cohesión Social e Inclusión Social. Intervención en zonas desfavorecidas (JUNTA DE ANDALUcíA, 2018b). 
El artículo analiza la Estrategia desde el punto de vista de su contenido en lo que se refiere a los objetivos, metodología e implementación y realiza una evaluación preliminar sobre cuáles son las dimensiones de la vulnerabilidad que considera para delimitar e intervenir en zonas desfavorecidas a través del análisis de los indicadores que utiliza. El concepto de vulnerabilidad urbana acoge múltiples dimensiones que interactúan entre sí (ALGUACIL \& al., 2014) y se refiere a la situación que la población ocupa en una escala de gradación entre la integración y la exclusión social. La vulnerabilidad se entiende, de este modo, como una zona de tránsito entre la zona de integración y la de exclusión, y en la que se conjugan y combinan múltiples factores desencadenantes. Desde este último punto de vista, el artículo basa su metodología de análisis de las dimensiones de la vulnerabilidad, en la utilizada en el "Informe sobre otros Observatorios de la Vulnerabilidad Urbana y su vinculación con las políticas urbanas de regeneración de barrios en Europa y España (HERNÁNDEZ \& al., 2020) en el que se identifican y analizan diversas herramientas (observatorios y/o estrategias) para la detección y/o intervención sobre la vulnerabilidad y/o pobreza urbana en Europa y en España. Esta metodología plantea un modelo de análisis de indicadores de vulnerabilidad urbana mediante su clasificación en seis dimensiones: sociodemográfica, socioeconómica, residencial, subjetiva, marco urbano y ambiental.

\section{Contexto}

\subsection{Antecedentes}

La intervención por parte de la Junta de Andalucía en las áreas de los municipios andaluces que sufren problemas de pobreza y exclusión social se remonta a mediados de los años 80 del siglo $X X$ a través de análisis para la identificación de zonas desfavorecidas y realizando inversiones gracias a la Comisión Delegada de Bienestar Social con el objetivo de mitigar las carencias presentes en estos territorios. Este tipo de intervenciones han sido continuadas desde aquel momento y se han llevado a cabo mediante planes y programas que contemplaban objetivos y áreas objeto de actuación diversos para las que han adoptado diferentes denominaciones (FIG. 2).

\begin{tabular}{|c|c|c|}
\hline Año & Plan /Programa asociado & $\begin{array}{l}\text { Nomenclatura de las zonas en riesgo de } \\
\text { exclusión social }\end{array}$ \\
\hline 1989 & \multirow{4}{*}{$\begin{array}{l}\text { Plan de Barriadas de Actuación Preferente } \\
\text { Decreto 202/1989 Plan de Barriadas de Actuación } \\
\text { Preferente }\end{array}$} & Barriadas de Actuación Preferente \\
\hline 1994 & & $\begin{array}{l}\text { Barriadas de Actuación Preferente } \\
\text { Barriadas con especiales necesidades }\end{array}$ \\
\hline 1995 & & Zonas con Especial Problemática Social \\
\hline 1998 & & \multirow{4}{*}{$\begin{array}{l}\text { Zonas con Necesidades de } \\
\text { Transformación Social (ZNTS) }\end{array}$} \\
\hline 2003 & $\begin{array}{l}\text { Plan Andaluz para la Inclusión Social 2003-2006 } \\
\text { ACUERDO de } 11 \text { de noviembre de 2003, del Consejo de } \\
\text { Gobierno, por el que se aprueba el Plan Andaluz para la } \\
\text { Inclusión Social. }\end{array}$ & \\
\hline 2006 & $\begin{array}{l}\text { Intervención coordinada de la Junta de Andalucía en } \\
\text { Zonas con Necesidades de Transformación Social. } \\
\text { Aprobado por la Comisión Política Andaluza } \\
\text { Sevilla, julio } 2006\end{array}$ & \\
\hline 2013 & $\begin{array}{l}\text { Decreto-ley } 7 / 2013 \text { de medidas extraordinarias y } \\
\text { urgentes para la lucha contra la exclusión social en } \\
\text { Andalucía }\end{array}$ & \\
\hline 2018 & $\begin{array}{l}\text { ERACIS: Estrategia Regional Andaluza para la Cohesión } \\
\text { e Inclusión Social. Intervención en Zonas } \\
\text { Desfavorecidas. } \\
\text { Acuerdo de } 28 \text { de agosto de } 2018 \text { del Consejo de } \\
\text { Gobierno de la Junta de Andalucía }\end{array}$ & Zonas Desfavorecidas Identificadas (ZDI) \\
\hline
\end{tabular}

FIG. 2 / Relación de las diferentes nomenclaturas que ha recibido las zonas desfavorecidas en Andalucía desde 1989 hasta 2018. 
En 1989 se aprueba un plan de actuación conjunta entre diferentes Consejerías mediante el Decreto 202/1989 Plan de Barriadas de Actuación Preferente (JUNTA DE ANDALUcía, 1989), con competencias en las diferentes áreas incluidas en el Plan: formación, animación sociocultural, inserción social, y urbanismo, infraestructuras y vivienda, estableciéndose tres niveles de coordinación (regional, provincial y de barrio). En el Decreto se identificaron 8 barriadas dentro del territorio andaluz de actuación preferente, una por cada capital de provincia. El impulso de esta política pública recayó inicialmente sobre la Consejería de Gobernación, pero será a partir de 1990 cuando la competencia la asuma la Consejería de Asuntos Sociales, responsable de la creación de la Oficina del Plan de Barriadas de Actuación Preferente y de la Comisión Interdepartamental de Barriadas de Actuación Preferente y en este año se identificaron un total de 11 barrios.

En 1991 la Consejería de Asuntos Sociales pone en marcha la actuación en estas áreas gracias a la concesión de subvenciones a entidades públicas y privadas sin ánimo de lucro que intervenían en ellas y en 1993 pasaron de 11 a 14 barrios identificados. En 1994, el Plan incorpora a las barriadas de actuación preferente, las barriadas con especiales necesidades, y en 1995 desaparecen las ayudas para las barriadas declaradas de actuación preferente y se incorporan ayudas para Zonas con Especial Problemática Social. Por último, en 1998 las zonas cambian su denominación a Zonas con Necesidades de Transformación Social (ZNTS), la cual se mantendrá hasta principios del siglo $\mathrm{XXI}$, momento en el que la regulación de las subvenciones para las actuaciones en estas zonas es muy similar a la anterior. Será en 2003 , con la aprobación del Plan Andaluz para la Inclusión Social 2003-2006 (JUNTA DE ANDALUCíA, 2003), cuando se incorpore esta nomenclatura en uno de sus objetivos generales: la "Intervención en Zonas con Necesidades de Transformación Social", y se pondrá de manifiesto la importancia de la administración local a la hora de implementar estas actuaciones a través de planes locales, definidos como

"los instrumentos mediante los cuales los Ayuntamientos podrán realizar, con la necesaria participación social, un diagnóstico de cada Zona, y a partir del modelo de intervención establecido por el Plan Andaluz para la Inclusión Social, adaptar a cada caso las estrategias que en el mismo se contienen para dar respuesta a la problemática planteada".
Esta definición de los planes locales lleva implícito un carácter de coordinación y cooperación entre ambas administraciones y a su vez tiene en cuenta la identidad de cada uno de los territorios bajo un mismo paraguas que es el de la intervención en zonas desfavorecidas de forma participada e integral.

En esta misma línea, en el año 2006, la Junta de Andalucía aprobó el documento "Intervención coordinada de la Junta de Andalucía en Zonas con Necesidades de Transformación Social" (JUNTA DE ANDAlucía, 2006) a través de la Comisión de Política Andaluza que se componía por seis consejerías (Innovación, Ciencia y Empresa; Empleo, Educación, Obras Públicas y Transporte; Salud, Igualdad y Bienestar Social), encargada de la toma de decisiones en el diseño de acciones y programas y la Comisión Técnica Andaluza (compuesta por Jefaturas de Servicio de las Direcciones Generales implicadas y el apoyo de asesorías técnicas) que elaboraba las metodologías de acción en estas zonas, en el cual se mencionaba

"la dificultad para coordinar los distintos recur-
sos que desde distintos ámbitos competenciales
llegan al territorio" y en este sentido era "im-
prescindible que los equipos de profesionales
involucrados en el territorio se sientan implica-
dos en un único proyecto: la transformación de
la zona, con independencia de la procedencia de
los recursos" abogando por la articulación de todos ellos en lo que se denominaron Planes de Zona. Estos instrumentos organizaban las intervenciones en base a los principios de: intersectorialidad, integralidad, participación, y flexibilidad en las fases de elaboración y participación.

El Decreto-ley 7/2013 de medidas extraordinarias y urgentes para la lucha contra la exclusión social en Andalucía (JUNTA DE ANDALUCíA, 2013), ya derogado, hace referencia a las Zonas con Necesidades de Transformación Social definiéndolas como "aquellos espacios urbanos concretos y físicamente delimitados, en cuya población concurran situaciones estructurales de pobreza grave y marginación social" y anexa una lista con la relación de las Zonas con Necesidades de Transformación Social que se habían identificado en el territorio andaluz, el número de zonas en los último diez años se multiplicó casi por cuatro, en este año eran 55 las zonas identificadas. Aclarada la definición, la normativa vigente en ese momento (CONSEJERÍA DE IGUALDAD Y Políticas Sociales, 2016) reguladora de las 

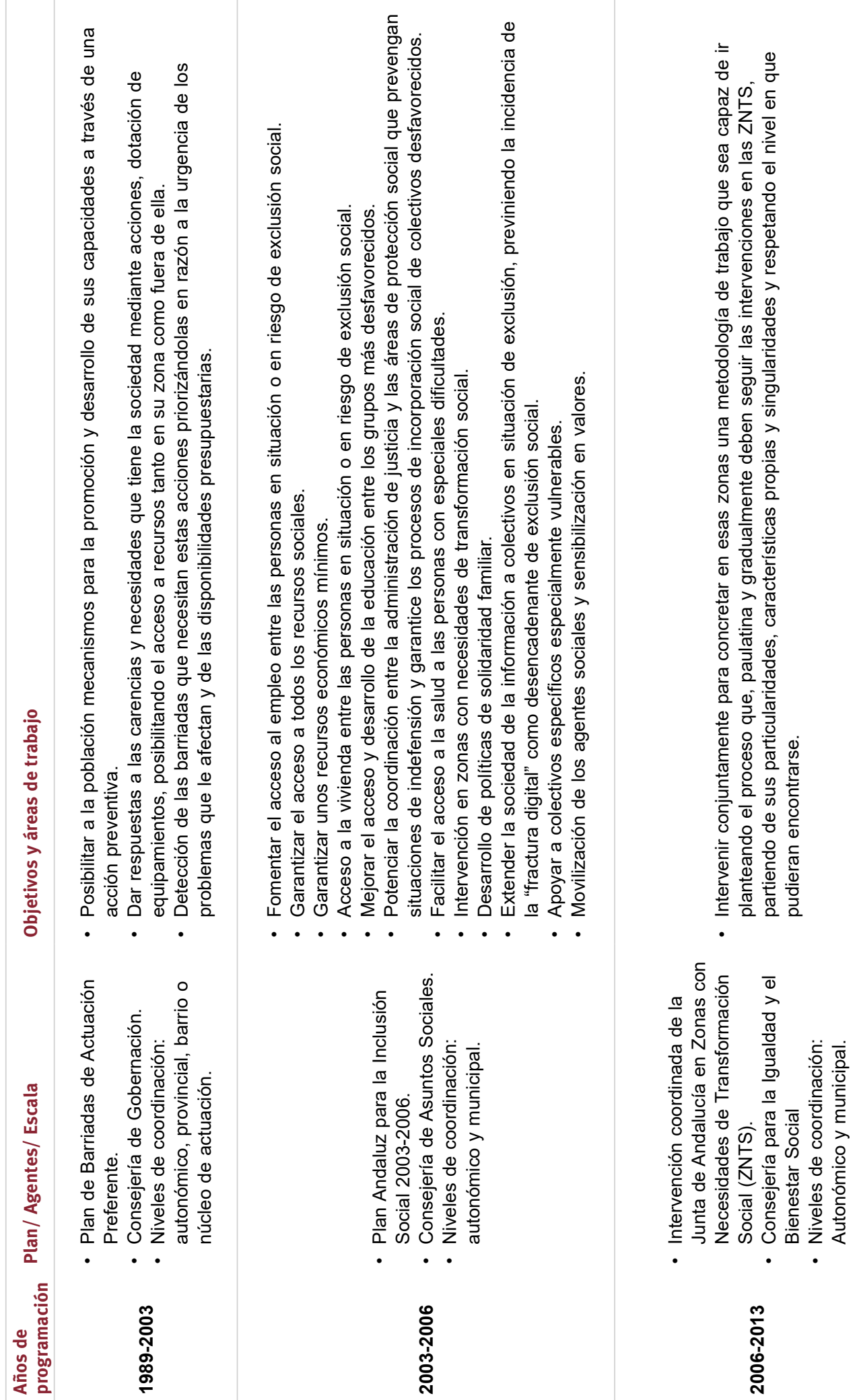

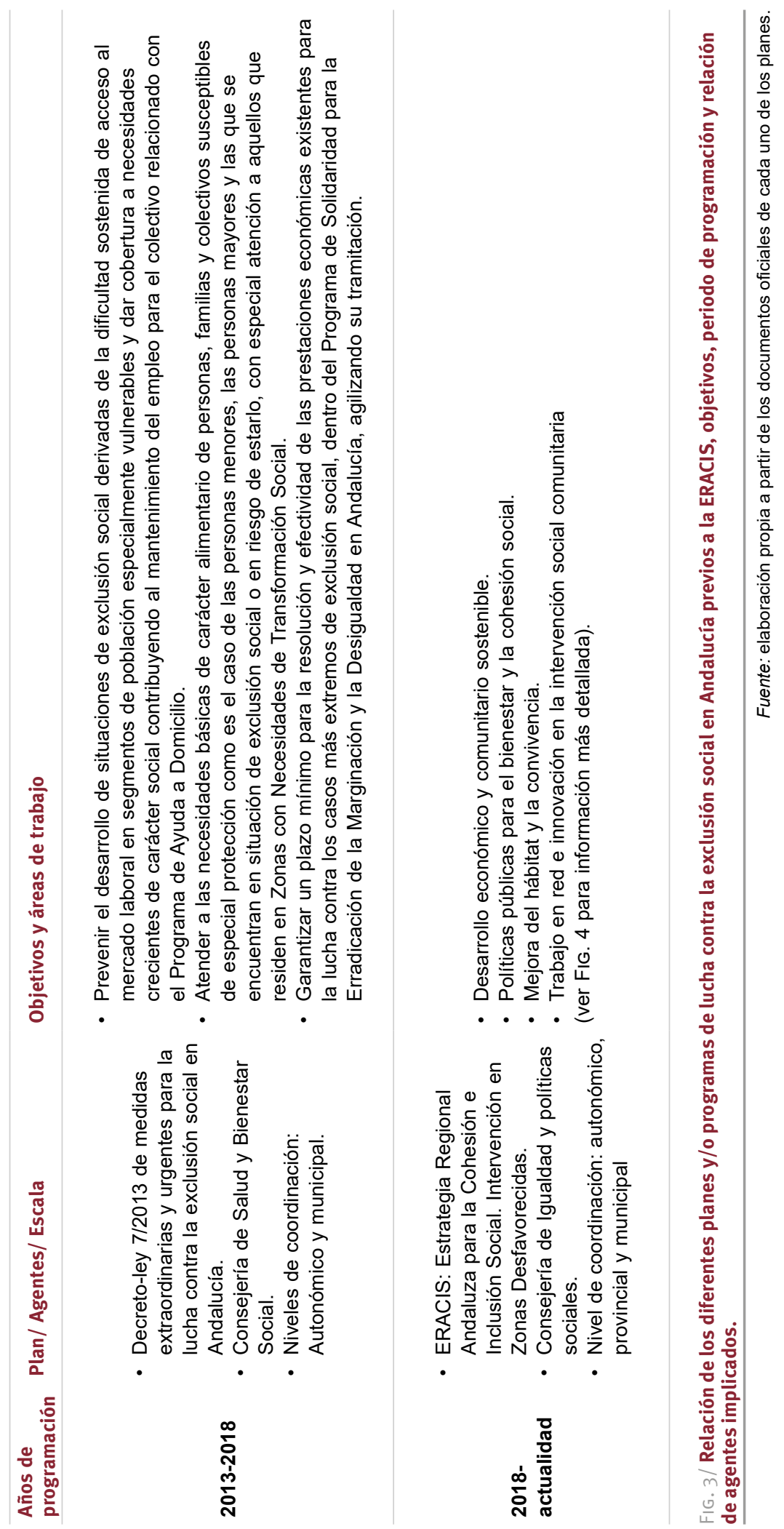
subvenciones a Zonas con Necesidades de Transformación Social (ZNTS) de la Consejería de Igualdad y Políticas Sociales, que data de 2017, añade a la definición anterior, que éstas

\begin{abstract}
"serán aquellas zonas en las que se aprecien problemas significativos en relación a las siguientes áreas: vivienda, deterioro urbanístico y déficit de las infraestructuras, equipamientos y servicios públicos; elevados índices de absentismo y fracaso escolar; altas tasas de desempleo junto y/o graves carencias formativas profesionales; significativas deficiencias higiénico-sanitarias o fenómenos de desintegración social".
\end{abstract}

Como conceptos subvencionables recoge: acciones de promoción e inserción socio laboral; acciones de intervención socio familiar; acciones de impulso de la participación social, fomento del asociacionismo y el voluntariado; acciones de sensibilización social; y acciones de integración social de colectivos con especiales necesidades.

La identificación de áreas necesitadas de intervención por presentar síntomas de desfavorecimiento y la aplicación de instrumentos de intervención sobre ellas basados en sistemas de gobernanza multinivel ha sido continua en Andalucía a lo largo de más de tres décadas. La ERACIS es, por tanto, la última generación de estos instrumentos e incorpora todo el acervo de la práctica anterior. El resumen de los objetivos y áreas de trabajo de los cinco planes desarrollados hasta el momento, así como los años de programación, agentes implicados y escalas de intervención se refleja en la FIG. 3.

\subsection{Marco general de la Estrategia}

Además de los antecedentes antes mencionados, que son clave para entender como Andalucía lleva más de treinta años apostando por políticas públicas para luchar contra la exclusión social y a favor de la cohesión social de forma integral, es necesario describir el marco general de políticas públicas y agendas urbanas al que se adhiere desde el punto de vista internacional y nacional, como describe el documento de la ERACIS, y que reflejan su vocación de integralidad.

Desde el punto de vista del marco internacional, hace especial mención a la Agenda 2030, citando los Objetivos de Desarrollo Sostenible (ODS) con los que se alinea. En este sentido menciona tanto el ODS1 "Poner fin a la pobreza" como al ODS11 "Lograr que las ciudades y los asentamientos humanos sean inclusivos, seguros, resilientes y sostenibles" y remarca aquellas metas de estos objetivos donde la ERACIS propone hacer hincapié a través de sus objetivos específicos que traduce en medidas operativas: reducir al menos a la mitad la población que vive en riesgo de pobreza en todas sus dimensiones; implementar medidas apropiadas para la protección social; asegurar el acceso a la vivienda y servicios básicos de todas las personas; aumentar la urbanización inclusiva y sostenible; y proporcionar el acceso universal a zonas verdes y espacios públicos seguros.

En el marco de política estatal, la estrategia se enmarca en el Plan Nacional de Acción para la Inclusión Social (MINISTERIO DE SANIDAD, SERVICIOS Sociales E IGUALDAD, 2014) cuyas competencias están ampliamente transferidas a las comunidades autónomas, cuyo Objetivo operativo 22 es mejorar las condiciones de seguridad, salubridad y habitabilidad de las viviendas de las familias y su entorno, con acompañamiento de programas sociales, que de manera operativa se refleja en su Actuación 161, el fomento del conocimiento de la ubicación geográfica de las zonas socialmente desfavorecidas a lo largo del territorio español mediante la elaboración de un mapa de barrios vulnerables con problemática social.

En el marco autonómico, la estrategia se enmarca en los preceptos del Estatuto de Autonomía de Andalucía, destacando el artículo 10.3 donde se incluye el objetivo de cohesión social con especial atención a colectivos y zonas desfavorecidas social y económicamente y el artículo 37.1. donde se expresa que las políticas públicas se centrarán en "la atención social a personas que sufran marginación, pobreza o exclusión y discriminación social", entre otros.

Por otra parte, y también en el marco autonómico, hace referencia a una gran variedad de políticas sectoriales que se están desarrollando en la zonas desfavorecidas, las cuales engloban diferentes dimensiones, lo que pone de manifiesto como la Estrategia pretende ser una política pública integral e integrada: políticas de servicios sociales (Plan Integral para la Inclusión de la Comunidad Gitana de Andalucía 2017-2020; II Plan Andaluz sobre Drogas y Adicciones 2016-2021; III Plan Integral para la Inmigración en Andalucía Horizonte 2016); políticas de educación (Proyecto Educativo Centro: planes de compensatoria, planes de apoyo y refuerzo (PROA), Aulas Temporales de Adaptación Lingüística (ATAL), Planes de Acompañamiento Lingüístico para el alumnado Inmigrante (PALI); Comunidades de Aprendizaje); políticas de salud (Atención a la Salud en Zonas con Necesidades de Transformación Social de Andalucía de 2004; IV Plan de Salud 2013-2020; 
Plan Local de Salud es la herramienta de las entidades locales); y políticas de vivienda (Ley 1/2010 de 8 marzo Reguladora del Derecho a la Vivienda; Plan de Vivienda y Rehabilitación de Andalucía 2016-2020).

\section{Objetivos y metodología en la ERACIS}

\subsection{Contenido de la herramienta}

La Estrategia Regional Andaluza para la Cohesión e Inclusión Social. Intervención en Zonas Desfavorecidas (ERACIS) se apoya en un diagnóstico sobre la situación de desigualdad y exclusión territorial en Andalucía que representa la base para la identificación y posterior selección de zonas desfavorecidas sobre las que se va a implementar las intervenciones. Esta implementación llega de la mano de su instrumento clave, los Planes Locales de Intervención en Zonas Desfavorecidas (PLIZD) para la intervención en barrios, elaborados de forma participada entre las administraciones públicas competentes, los agentes sociales asociados al barrio y la ciudadanía residente en esos territorios y donde la coordinación de las actuaciones propuestas en ellos depende de la administración local, responsable del cumplimiento de objetivos y criterios establecidos en dichos planes.

La ERACIS define los cuatro ejes de actuación anteriormente mencionados (desarrollo económico y comunitario sostenible; políticas públicas para el bienestar social y la cohesión social; mejora del hábitat y la convivencia; y trabajo en red e innovación en la intervención social comunitaria), sobre los cuales describe una serie de objetivos específicos asociados a cada uno de ellos y asocia a éstos una serie de agentes responsables. Estos objetivos específicos a su vez llevan asociados una serie de medidas a implementar junto a la descripción de los agentes responsables de llevarlas a cabo. En este sentido, se trata de una estrategia que vas más allá de enunciar unos principios rectores y unos objetivos respondiendo a los problemas y necesidades de la región porque, además, propone una serie de medidas para la implementación desde la práctica, o lo que en políticas públicas se denomina dimensión operativa (AGENCIA ESTATAL DE EVALUACIÓN DE POLÍTICAS, AEVAL, 2015). Esta dimensión operativa, trasladada a la escala municipal, se verá completada con la realidad de cada territorio a través de los planes locales, Planes Locales de Zonas Desfavorecidas (PLZD). Cabe destacar igualmente el esfuerzo por interrelacionar los diferentes agentes implicados en cada uno de los objetivos y medidas al identificar la responsabilidad en cada una de las escalas administrativas y gubernamentales (regional, provincial, local).

\subsection{Objetivos de la herramienta}

La finalidad principal de la Estrategia Regional Andaluza para la Cohesión e Inclusión Social se describe como: "actuar sobre las zonas de los pueblos y ciudades donde se registren situaciones graves de exclusión social y/o donde existan factores de riesgo de que se produzcan e igualmente sobre el contexto general del municipio, promoviendo que la territorialidad no sea un factor de exclusión."

La ERACIS consta de doce principios rectores: enfoque comunitario; integración de la perspectiva de género; empoderamiento y autonomía; integralidad; cooperación público-privada; participación de la ciudadanía y agentes intervinientes; coordinación; prevención; utilización preferente e inteligente de los activos en la zona; solidaridad y equidad; enfoque centrado en las personas y en las familias; $y$ fomento de la interculturalidad y diversidad humana.

A través de estos principios rectores establece cuatro ejes de actuación con un enfoque integral y comunitario que facilite a las personas residentes en zonas desfavorecidas el acceso a los sistemas de protección social, especialmente a los de salud, vivienda, educación y empleo, así como a otros servicios públicos. Estos cuatro ejes se definen del siguiente modo:

- Desarrollo económico y comunitario sostenible: busca la mejora de las carencias del modelo de desarrollo social, económico, urbano y medioambiental en el que se genera la exclusión social y que ocasionan las condiciones de pobreza extrema.

- Políticas públicas para el bienestar y la cohesión social: pretende modificar la lógica de intervención de los instrumentos de políticas públicas de educación, salud, servicios sociales, empleo, urbanismo y servicios públicos urbanos de cara a la mejora de la calidad de vida y la inclusión social.

- Mejora del hábitat y la convivencia: busca solucionar los problemas del medio urbano relacional, con la integración del barrio en el resto de la ciudad por lo que plantea la mejora de la coordinación entre las políticas locales y autonómicas. 
- Trabajo en red e innovación en la intervención social comunitaria: trata de evitar la segregación social de las zonas desfavorecidas que produce una mala imagen de éstas y el estigma a sus residentes como una realidad presente.

Estos cuatro ejes contienen cincuenta y cuatro objetivos operativos (FIG. 4) y ciento veintinueve medidas a implementar, donde algunas resultan de obligada incorporación en los Planes Locales de Intervención en Zonas Desfavorecidas (PLZD) que presenten los municipios en desarrollo de la estrategia regional.

\subsection{Metodología de la herramienta}

La Estrategia Regional realiza distintos análisis a diferentes escalas, tanto desde el punto vista cuantitativo como cualitativo, para caracterizar e identificar el fenómeno de la pobreza y de la exclusión social en Andalucía e intervenir

\begin{tabular}{|c|c|c|}
\hline Ejes & $\begin{array}{l}\text { № objetivos } \\
\text { operativos }\end{array}$ & Áreas intervención \\
\hline $\begin{array}{l}\text { Eje 1. Desarrollo } \\
\text { económico y comunitario } \\
\text { sostenible }\end{array}$ & 7 & $\begin{array}{l}\text { - Empleo } \\
\text { - Comercio } \\
\text { - Empresa } \\
\text { - Economía Social } \\
\text { - Realidad socioeconómica }\end{array}$ \\
\hline $\begin{array}{l}\text { Eje 2. Políticas públicas } \\
\text { para el bienestar social y } \\
\text { la cohesión social }\end{array}$ & 21 & $\begin{array}{l}\text { - Educación } \\
\text { - Brecha digital } \\
\text { - Brecha de género } \\
\text { - Drogadicción } \\
\text { - Salud } \\
\text { - Rehabilitación de viviendas } \\
\text { - Infravivienda } \\
\text { - Accesibilidad vivienda y espacio público } \\
\text { - Desahucios } \\
\text { - Servicios sociales y comunitarios } \\
\text { - Ocio inclusivo } \\
\text { - Conciliación (personal-familiar-laboral) } \\
\text { - Inmigración } \\
\text { - Etnia gitana } \\
\text { Políticas activas de empleo }\end{array}$ \\
\hline $\begin{array}{l}\text { Eje } 3 \text {. Mejora del hábitat } \\
\text { y la convivencia }\end{array}$ & 13 & $\begin{array}{l}\text { - Equipamientos y zonas verdes } \\
\text { - Movilidad urbana y metropolitana } \\
\text { - Convivencia } \\
\text { - Vigilancia } \\
\text { - Revitalizar espacios públicos y/o de encuentro } \\
\text { - Diseño de PLIZD } \\
\text { - Acceso a servicios públicos } \\
\text { - Identidad cultural } \\
\text { - Participación }\end{array}$ \\
\hline $\begin{array}{l}\text { Eje 4. Trabajo en red e } \\
\text { innovación en la } \\
\text { intervención social } \\
\text { comunitaria }\end{array}$ & 13 & $\begin{array}{l}\text { - Innovación y desarrollo económico } \\
\text { - Formación de agentes implicados } \\
\text { - Estrategias intervención social } \\
\text { - Instrumentos de trabajo multidisciplinar } \\
\text { - Mejora y trasformación de la imagen (estigmatización) } \\
\text { - Desarrollo de PLIZD } \\
\text { - Coordinación Administración Pública } \\
\text { - Tejido asociativo }\end{array}$ \\
\hline
\end{tabular}

FIG. 4/ Ejes de actuación, objetivos específicos de la ERACIS y áreas en las que se inscriben.

Fuente: elaboración propia en base a la Estrategia Regional Andaluza para la Cohesión Social e Inclusión Social. Intervención en zonas desfavorecidas (JUNTA DE ANDALUCÍA, 2018b).. 
en aquellos territorios que define como Zonas Desfavorecidas ${ }^{1}$. Estos análisis se han realizado a partir de los indicadores disponibles en cada caso, de manera que se pueda valorar la situación respecto al territorio nacional e internamente entre municipios, e incluso entre diferentes zonas de un mismo municipio. Estas escalas, por lo tanto, van desde lo regional en comparación con lo nacional a lo municipal, para acabar con la escala de análisis inframunicipal. A continuación, se detallan los indicadores utilizados en cada uno de sus análisis.

\subsubsection{Análisis socioeconómico del marco general: regional y municipal}

Los indicadores que comparan la región con el territorio nacional y que se definen en la ERACIS de cara a realizar un análisis del marco general a nivel regional y a nivel municipal se refieren a dos grupos de temas: capital social y económico, y capital económico, con 5 y 10 indicadores respectivamente. Aunque en este nivel de análisis predomina la dimensión socioeconómica de la vulnerabilidad, con 11 indicadores, también se contempla la dimensión sociodemográfica, con 3 indicadores, y la residencial, con un indicador (FIG. 5).

\subsubsection{Análisis socioeconómico a nivel inframunicipal}

Para identificar, caracterizar y diagnosticar las zonas de ámbitos inferiores al municipio donde están presentes situaciones de exclusión social la Estrategia plantea la utilización del ámbito espacial de la sección censal, con un total de 5.796 secciones censales en Andalucía en el momento de redacción de la Estrategia (JUNTA DE ANDALUCíA, 2018b). Sin embargo, la ERACIS no delimita directamente las áreas desfavorecidas, sino que remite su delimitación concreta y precisa al marco de los planes locales a cargo de los ayuntamientos y las diputaciones, y se limita al establecimiento de los indicadores de delimitación y la definición preliminar de las zonas desfavorecidas y que deberán ser una prioridad de intervención en los referidos planes locales.

La Estrategia destaca el indicador de renta familiar disponible para medir la pobreza, sin embargo, acude a variables proxy de renta para

\begin{tabular}{|c|c|c|}
\hline \multicolumn{2}{|c|}{ Indicadores que intervienen en el diagnóstico regional y municipal de la ERACIS } & Dimensiones \\
\hline \multirow{5}{*}{$\begin{array}{l}\text { Indicadores de } \\
\text { capital social } \\
\text { y económico }\end{array}$} & Renta media por persona & Socioeconómica \\
\hline & Renta media por hogar & Socioeconómica \\
\hline & Tasa de Paro & Socioeconómica \\
\hline & Exclusión residencial & Residencial \\
\hline & Indicadores de salud & Sociodemográfico \\
\hline \multirow{10}{*}{$\begin{array}{l}\text { Indicadores de } \\
\text { capital } \\
\text { humano }\end{array}$} & Nivel de instrucción alcanzado & Socioeconómica \\
\hline & Tasa de absentismo escolar & Socioeconómica \\
\hline & Tasa de alfabetización & Socioeconómica \\
\hline & \% Población que finaliza estudios primarios & Socioeconómica \\
\hline & Tasa de abandono escolar total & Socioeconómica \\
\hline & Tasa de abandono escolar. Mujeres & Socioeconómica \\
\hline & Tasa de abandono escolar. Hombres & Socioeconómica \\
\hline & Envejecimiento & Sociodemográfica \\
\hline & Tasa de dependencia & Socioeconómica \\
\hline & Población de origen extranjero & Sociodemográfica \\
\hline
\end{tabular}

FIG. 5/ Indicadores de análisis del marco a nivel regional y municipal.

Fuente: elaboración propia en base a la Estrategia Regional Andaluza para la Cohesión Social e Inclusión Social. Intervención en zonas desfavorecidas (JUNTA DE ANDALUCíA, 2018b).

1 "definidas como aquellos espacios urbanos claramente de-
limitados, en cuya población concurran situaciones estructu-
rales de pobreza grave y marginación social, y en los que
sean significativamente apreciables problemas en las si-
guientes materias: vivienda, deterioro urbanístico y déficit de infraestructura, equipamiento y servicios públicos; elevados índices de absentismo y fracaso escolar; altas tasas de desempleo junto a graves carencias formativas profesionales; significativas deficiencias higiénico sanitarias y fenómenos de desintegración social" (JUNTA DE ANDALUcíA, 2018b). 
poder medir a nivel de sección censal. Por ello, selecciona la variable paro-desempleo como la mejor que explica la distribución de la renta a dicha escala. Este indicador se completa con otros indicadores: el nivel de analfabetismo de la población potencialmente activa, el estado de conservación de la vivienda principal o el peso de la población inmigrante. Existen otros estudios previos, a escala de sección censal, como el Análisis urbanístico de Barrios Vulnerables en España (MINISTERIO DE FOMENTO, 2016) donde se utilizaban indicadores similares: tasa de paro, renta disponible, inmigración y condiciones de la vivienda para determinar espacios de vulnerabilidad urbana, y en los que, como veremos más adelante, la Estrategia se apoya a la hora de desarrollar su metodología de detección de las zonas desfavorecidas.

En la FIG. 6 se recogen los 8 indicadores de análisis utilizados a nivel Inframunicipal, 4 de ellos referidos a la dimensión socioeconómica de la vulnerabilidad, 2 a la sociodemográfica y otros 2 a la residencial.

El análisis de estas variables a escala inframunicipal ha permitido a la Estrategia identificar un conjunto de áreas estadísticas (1.407) como agregación de las secciones censales presentes en Andalucía por criterio de proximidad relativa y homogeneidad de sus características. A partir de este análisis de áreas estadísticas, se han incluido una serie de indicadores que dan idea de la respuesta de la población a la existencia de los sistemas de protección social (educación, salud, vivienda, salario social, etc.) para llegar a una mayor aproximación de la problemática de la exclusión social. Por ello, la estrategia ha identificado 187 áreas estadísticas con mayor riesgo de padecer situaciones de pobreza y/o exclusión social, a las cuales se han denominado Zonas Desfavorecidas Identificadas (ZDI), aunque cabe recordar que la delimitación precisa y concreta se hará en el marco de los planes locales. Estas 187 ZDI se localizan en 97 municipios $(12,7 \%$ del total regional) y en ellas residen casi un $17 \%$ de la población andaluza. Las ZDI no permiten identificar las situaciones de exclusión social en su interior. Sin embargo, si contribuyen a focalizar el problema sobre las áreas urbanas con mayor riesgo de exclusión social gracias a otros indicadores como el de personas perceptoras del ingreso Mínimo de Solidaridad por 1.000 habitantes o el porcentaje de población inmigrante residente.

Indicadores de diagnóstico inframunicipal ZDI

Dimensión

Población: Población que residen en una ZDI en cada ámbito. (Población en ZDI/ Socioeconómica

Población total ámbito) * 100

Población > 75 años: \% Población de 75 y más años que reside en una ZDI en cada ámbito. (Población de 75 y más años que reside en ZDI / Población de 75 y más años en el ámbito) * 100

Población sin estudios 16-65 años: \% Población analfabeta o sin estudio que reside en una ZDI en cada ámbito. (Población analfabeta o sin estudio que reside en una ZDI/ Población analfabeta o sin estudio que reside en el ámbito) *100

Población Estudios de tercer grado: \% Personas con estudios de tercer grado que reside en una ZDI en cada ámbito. (Personas con estudios de tercer grado que residen Sociodemográfica en una ZDI/ Personas con estudios de tercer grado que residen en el ámbito) *100

Población activa: \% de población activa que reside en una ZDI en cada ámbito. (Población activa que residen en ZDI / Población activa del ámbito) *100

Sociodemográfica

Población parada: \% de población parada que reside en una ZDI en cada ámbito. Socioeconómica (Población parada que reside en una ZDI / Población parada del ámbito) *100

Vivienda cedida gratis: \% de Viviendas cedida gratis o a bajo precio en una ZDI en cada ámbito. (Viviendas cedida gratis o a bajo precio en ZDI / Viviendas cedida gratis o a bajo precio del ámbito) *100

Socioeconómica

Vivienda edificio en mal estado: \% Vivienda en edificios en estado ruinoso, malo o deficiente en una ZDI en cada ámbito. (Vivienda en edificios en estado ruinoso, malo o deficiente en ZDI / Vivienda en edificios en estado ruinoso, malo o deficiente del ámbito) *100

Residencial

IG. 6/ Indicadores de análisis del marco a nivel Inframunicipal.

Fuente: elaboración propia a partir de la Estrategia Regional Andaluza para la Cohesión e Inclusión Social. Intervención en Zonas Desfavorecidas (JuNTA DE ANDALucía, 2018b). 
La metodología de delimitación seguida por la ERACIS presenta similitudes con la planteada por el Instituto Juan de Herrera de la Universidad Politécnica de Madrid y el Ministerio de Fomento para el Catálogo de Barrios Vulnerables de España, realizado para los años 1991, 2001 y 2011, y en el que se emplea un doble proceso de delimitación realizado en dos fases: delimitación de perímetros estadísticos (áreas estadísticas vulnerables) mediante agregación de secciones censales que superan un determinado valor de referencia para los indicadores, y delimitación de perímetros urbanísticos (barrios vulnerables) en los que se precisan los primeros en base a criterios morfotipológicos y de estructura urbana (HERNÁNDEZ \& al. 2018).

La elaboración del Mapa de Zonas Desfavorecidas (FIG. 7) se ha realizado en base a un proceso de identificación (detección) de Zonas Desfavorecidas Identificadas (ZDI), como se ha descrito previamente y para el que la Estrategia recoge las siguientes conclusiones:

- La Junta de Andalucía ha identificado 187 áreas estadísticas, de las 5.796 secciones censales, formadas por áreas entre 3.500 y 30.000 habitantes censados, aunque en ocasiones han mantenido zonas menores donde existen importantes problemas de pobreza y/o exclusión social. Estas áreas han sido denominadas Zonas Desfavorecidas Identificadas (ZDI).

- Dentro de las ZDI, ha seleccionado aquellas con mayores riesgos de exclusión social a través de la aplicación de tres metodologías: el Análisis Urbanístico de Barrios Vulnerables de España de 1991, 2001 y 2011 del actual Ministerio de Transportes, Movilidad y Agenda Urbana (MINISTERIO DE FOMENTO, 2016); el Proyecto de Investigación sobre "Condiciones de Habitabilidad de la población desfavorecida. Análisis cartográficosocial de Andalucía" de la Universidad de Granada (EGEA \& al., 2008); y la Metodología elaborada por el equipo técnico Ate Clave $^{2}$ utilizando análisis factorial de componentes principales aplicado a 18 indicadores de todas las dimensiones implicadas (demografía, actividad económica, inmigración,

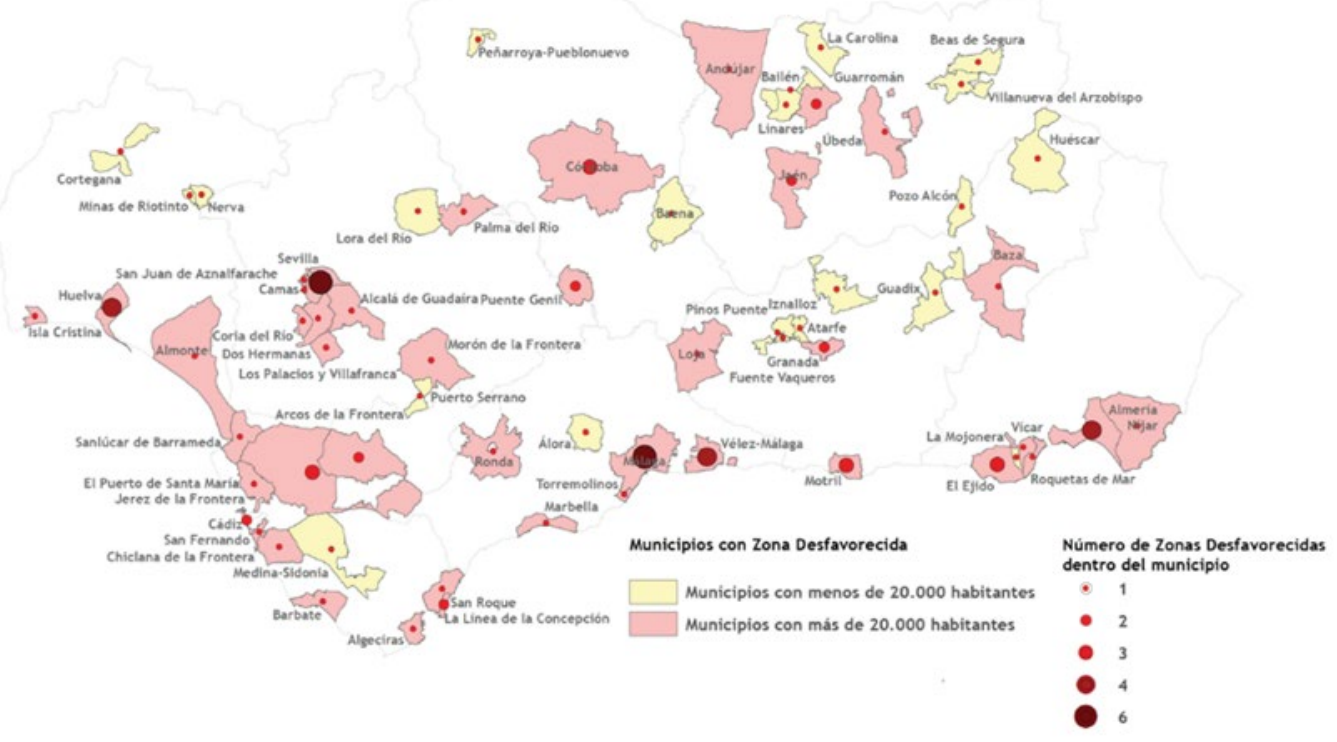

FIG. 7 / Municipios con Zonas Desfavorecidas en Andalucía.

Fuente: Estrategia Regional Andaluza para la Cohesión Social e Inclusión Social. Intervención en zonas desfavorecidas (JUNTA DE ANDALUCíA, 2018b).

2 Esta metodología a la que hace referencia el documento de la ERACIS no figura en la bibliografía de la propia
Estrategia y no se han localizado más referencias sobre ella para la redacción de este artículo. 
vivienda y salud) y agrupando las zonas en cuatro grupos mediante análisis clúster.

- Paralelamente al análisis socioeconómico cuantitativo, realizaron una serie de entrevistas cualitativas a diferentes agentes que intervienen en esas zonas desfavorecidas identificadas.

- A su vez han incorporado aquellas Zonas con Necesidades de Transformación Social (ZNTS) que durante los años 2016 y 2017 obtuvieron subvención y aquellas zonas que, según datos e información existente en las Delegaciones Territoriales y en los Servicios Centrales de la Consejería de Igualdad y Políticas Sociales, han sido propuestas por la necesidad detectada de una intervención integral.

La Estrategia, una vez identificadas las 187 ZDI, realiza una selección de esas zonas basada en cuatro criterios:

A. La presencia acumulada en la zona de alto índice de paro, alta presencia de población inmigrante de diferentes nacionalidades y/o registrar una baja respuesta a la prestación de los servicios públicos educativos y sanitarios.

B. La existencia de una elevada concentración del parque público de vivienda.

C. La existencia de graves problemas de seguridad y/o convivencia.

D. El estudio de la trayectoria e información disponible de intervención social en zonas propuestas por las Delegaciones Territoriales y los Servicios Centrales de la Consejería de Igualdad y Políticas Sociales.

En consecuencia, de este último filtro, la estrategia ha seleccionado 99 ZDI. Identificadas las zonas donde intervenir, los Ayuntamientos serán los responsables en cada uno de los municipios de implementar la estrategia a través del diseño de un plan local, el Plan Local de Intervención de Zonas Desfavorecidas (PLZD) y ampliarán el diagnóstico regional a nivel inframunicipal con el objetivo de justificar la zona elegida para llevar a cabo la intervención donde se integren las medidas de agentes públicos y privados que actúan en ellas, para afrontar los problemas de pobreza y exclusión. Las zonas donde se implementen las acciones serán delimitadas por los Ayuntamientos o por las Diputaciones Provinciales si el municipio es mayor de 20.000 habitantes; esta delimitación tiene la obligatoriedad de referirse a la zona o una parte de las zonas que en la Estrategia ha sido identificada como desfavorecida.

\subsubsection{Análisis cualitativo}

La Estrategia paralelamente realiza un análisis cualitativo en las zonas a través de las percepciones de la situación en ellas por parte de los actores que están interviniendo en materia de políticas sociales y/o pertenecientes a entidades sin ánimo de lucro. La información se ha recopilado y analizado mediante un doble proceso de documentación y observación y han realizado cerca de cuatrocientas entrevistas abiertas semiestructuradas. Las entrevistas que realizaron giraron en torno a materias como: el tiempo, la burocracia, los mecanismos en la toma de decisiones, la falta de personal, los espacios de relación, la distancia y ubicación de entidades y recursos, la brecha digital, la coordinación entre los miembros de la red y entidades, la existencia de duplicidades, las metodologías y el capital social. Gracias a este trabajo de campo la estrategia recoge una serie de conclusiones en relación a estas zonas en base a los temas tratados: inexistencia de intervención integral y horizontal en estas zonas, carencia de recursos, solapamiento de programas, existencia de cierta prevalencia hacia un enfoque intervencionista frente al comunitario, y por último percepción de un tejido social débil y una capacidad de cooperación debilitada.

\subsection{Seguimiento y evaluación de la Estrategia}

La Estrategia contiene un Sistema de Seguimiento y Evaluación con el fin de conocer el grado de ejecución de los objetivos propuestos, de cara a identificar si existen o no desviaciones en la implementación de éstos; tener consciencia de situaciones no previstas en la Estrategia $y$, en este sentido, tener la capacidad de reorientar ésta si fuese necesario; $y$, por último, determinar el impacto alcanzado con las acciones desarrolladas. Establece que la evaluación se lleve a cabo en dos tiempos: a medio camino de ejecución e inmediatamente después de la finalización del periodo de vigencia a través de un panel de indicadores, una ficha específica de indicador, otra ficha de seguimiento, un informe de seguimiento y un informe de evaluación. En la FIG. 8 se muestran los indicadores de seguimiento y evaluación que recoge la estrategia y 
que podrán incrementarse y/o modificarse por la Consejería de Igualdad y Políticas Sociales en función de las necesidades. Respecto a las dimensiones de los indicadores de seguimiento y evaluación, en este caso, encontramos una diferencia con relación a los de diagnóstico, y es la presencia de dos indicadores que se refieren a la dimensión subjetiva, entendiendo ésta como la percepción que tienen los beneficiarios y los trabajadores respecto a las medidas implementadas por la Estrategia. Destaca, por lo tanto, la importancia de visibilizar la opinión de las personas sobre su entorno y directamente afectadas por la implementación de la herramienta.

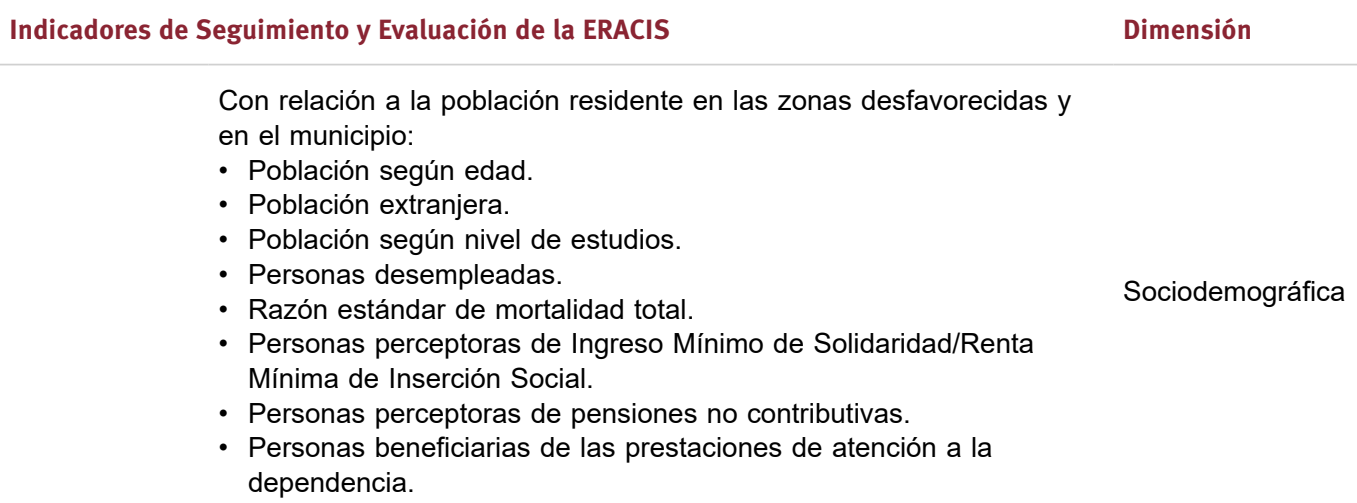

Con relación a la población residente en las zonas desfavorecidas y en el municipio:

- Población según edad.

- Población extranjera.

- Población según nivel de estudios.

- Personas desempleadas.

- Razón estándar de mortalidad total. Sociodemográfica

- Personas perceptoras de Ingreso Mínimo de Solidaridad/Renta Mínima de Inserción Social.

- Personas perceptoras de pensiones no contributivas.

- Personas beneficiarias de las prestaciones de atención a la dependencia.

Indicadores cuantitativos

Con relación a la población beneficiaria directa de los Planes Locales de Intervención en Zonas Desfavorecidas:

- Todas las variables contenidas en el Registro de participantes.

- Participantes en situación o riesgo de exclusión social que buscan Sociodemográfica trabajo, se integran en los sistemas de educación o formación, obtienen una cualificación u obtienen un empleo, incluido por cuenta propia, tras su participación.

Con relación a los recursos humanos del Desarrollo de la ERACIS.

- Personas trabajadoras según sexo, categoría laboral, duración del Socioeconómica contrato, jornada semanal de trabajo y coste laboral.

Con relación a los recursos económicos

- Cuantía presupuestaria invertida en cada zona desfavorecida

Socioeconómica

Con relación a los espacios de gobernanza

- Acuerdos tomados.

- Entidades que la forman.

Sociodemográfica

- Productos generados

Indicadores cualitativos

Con relación a las personas beneficiarias de las actuaciones y del personal empleado

- Grado de satisfacción de las personas beneficiaria en las diferentes actuaciones en las que participan.

Subjetiva

- Grado de satisfacción de las personas contratadas con el desarrollo del Plan Local de Intervención en zonas desfavorecidas/ ERACIS 


\section{Instrumentos de acción}

\subsection{Agentes en la herramienta}

La Estrategia Regional Andaluza para la Cohesión e Inclusión Social (ERACIS) es claramente una herramienta de cooperación y coordinación entre agentes institucionales, sociales y privados, donde las responsabilidades están claramente repartidas. La herramienta ha sido impulsada por la Consejería de Igualdad y Políticas Sociales, participada por distintos departamentos de la Junta de Andalucía y aprobada por Consejo de Gobierno, pero el desarrollo de sus objetivos, medidas y actuaciones se articula a través de diferentes entidades y agentes que se resumen en la FIG. 9 en relación con la función que desempeñan en cada una de las fases del proceso. Por otra parte, teniendo en cuenta que los Planes Locales de Intervención en Zonas Desfavorecidas (PLIZD) son los instrumentos de acción clave en la implementación de la estrategia, éstos a su vez tienen su estructura propia de gobernanza y organización como se muestra en la misma FIG. 9.

La Estrategia describe claramente todos los agentes que han sido partícipes en su elaboración y que forman parte de la implementación de ésta, motivación que subraya de nuevo la intención de que se constituya como una política pública integral y de gobernanza transversal.

\subsection{Los Planes Locales de Intervención en Zonas Desfavorecidas (PLIZD)}

El instrumento de acción clave de la Estrategia son los Planes Locales de Intervención en Zonas Desfavorecidas (PLIZD) para la intervención en barrios, los cuales serán elaborados de forma participada entre las administraciones públicas competentes, agentes sociales que intervienen en el barrio y la ciudadanía que reside en esos territorios, siendo la administración local la que coordina las actuaciones en relación a los objetivos y criterios establecidos en dichos planes.

La principal función de los PLIZD es la de facilitar y apoyar la articulación de proyectos comunes donde quepan todos los agentes para la transformación de la zona. Las entidades privadas que quieran participar en el desarrollo de la Estrategia y ser partícipes de la financiación

\begin{tabular}{|c|c|c|c|c|}
\hline Agentes & Diseño & Aprobación & Desarrollo & $\begin{array}{l}\text { Seguimiento y } \\
\text { evaluación }\end{array}$ \\
\hline \multicolumn{5}{|l|}{ Agentes ERACIS } \\
\hline Consejería de Igualdad y Servicios Sociales & $\mathrm{X}$ & & $\mathrm{X}$ & $\mathrm{X}$ \\
\hline Comisión Interdepartamental & $\mathrm{X}$ & & & \\
\hline Comité Asesor & $x$ & & & \\
\hline $\begin{array}{l}\text { Foro de agentes implicados en las zonas } \\
\text { desfavorecidas }\end{array}$ & $\mathrm{X}$ & & & \\
\hline Consejo de Gobierno & & $\mathrm{x}$ & & \\
\hline $\begin{array}{l}\text { Grupo de trabajo Autonómico de Zonas } \\
\text { Desfavorecidas }\end{array}$ & & & $\mathrm{x}$ & $\mathrm{X}$ \\
\hline Grupo de trabajo provincial de Zonas Desfavorecidas & $x$ & & $\mathrm{x}$ & $\mathrm{X}$ \\
\hline \multicolumn{5}{|l|}{$\begin{array}{l}\text { Agentes PLIZD (Planes Locales de Intervención en } \\
\text { Zonas Desfavorecidas) }\end{array}$} \\
\hline Consejería de Igualdad y Servicios Sociales & & $\mathrm{x}$ & $\mathrm{X}$ & $\mathrm{X}$ \\
\hline $\begin{array}{l}\text { Grupo de trabajo Autonómico de Zonas } \\
\text { Desfavorecidas }\end{array}$ & & & $\mathrm{X}$ & $\mathrm{X}$ \\
\hline Grupo de trabajo provincial de Zonas Desfavorecidas & & & $\mathrm{X}$ & $\mathrm{X}$ \\
\hline Órganos competentes de las Entidades Locales & $\mathrm{X}$ & & $\mathrm{X}$ & $\mathrm{X}$ \\
\hline Comisión Local de Impulso Comunitario & $\mathrm{X}$ & & $\mathrm{x}$ & $\mathrm{X}$ \\
\hline Mesas Sectoriales y/o zonas & $\mathrm{X}$ & & $\mathrm{X}$ & $\mathrm{X}$ \\
\hline Red de Inclusión Andaluza en Zonas Desfavorecidas & $x$ & & $\mathrm{x}$ & $\mathrm{X}$ \\
\hline
\end{tabular}

Fuente: elaboración propia en base a la Estrategia Regional Andaluza para la Cohesión Social e Inclusión Social. Intervención en zonas desfavorecidas (JUNTA DE ANDALUcía, 2018b). 
tendrán que hacerlo a través de los planes locales gracias a las convocatorias de subvenciones bienales de ámbito regional que se presentarán para su aprobación en la Consejería de Igualdad y Políticas Sociales.

En los PLIZD aparecen dos ideas fundamentales de la Estrategia: la participación y los agentes de cambio, entendidos éstos como la administración, los agentes sociales y la ciudadanía residente.

Actualmente existen casi cuarenta planes locales aprobados, presentes en todas las provincias de Andalucía de un total de 99 de ZDI en el territorio, elaborándose un 39\% de los PLZDI posibles en los dos años que lleva implementándose la estrategia desde 2018 (FIG. 10).

\section{Conclusiones}

Analizando la Estrategia en la actualidad, se hace necesario tener en cuenta la existencia de diferentes marcos de referencia ante los retos urbanos que fueron aprobados con posterioridad, entre los que destacan las agendas urbanas como herramientas de marco básico de actuación en nuestras ciudades. En este sentido, el diseño de la estrategia es coetáneo a la aprobación de la Agenda Urbana Andaluza (JUNTA DE ANDALUCíA, 2018c), la cual se aprobó por acuerdo de Gobierno veinte días después que la ERACIS. La agenda en su dimensión social asociada al reto 3 "promover la ciudad equitativa" señala en su eje 9 "Desarrollar programas de intervención en zonas desfavorecidas, atendiendo a la vulnerabilidad en todas sus dimensiones", es decir, la Estrategia es una pieza clave en lo que podemos considerar el plan de acción de la agenda urbana andaluza. A sí mismo, la publicación de la Agenda Urbana Española (MINISTERIO DE FOMENTO, 2019) fue también posterior, aunque ésta llevaba gestándose desde el año 2016, y recoge igualmente en su objetivo estratégico 6 "Fomentar la cohesión social y buscar la equidad”, la necesidad de identificar los barrios con mayor vulnerabilidad social, económica y ambiental como áreas de actuación preferente para acabar con la exclusión social y la desigualdad urbana. A su vez, el Plan Vive en Andalucía, de vivienda, rehabilitación y regeneración urbana de Andalucía 2020-2030 (JUNTA DE ANDALUcíA, 2020) señala la necesidad de avanzar en el estado de bienestar promoviendo ciudades más humanas mediante la rehabilitación, especialmente de las zonas más desfavorecidas de Andalucía, considerando los ámbitos de actuación establecidos en la Estrategia Regional Andaluza para la Cohesión e Inclusión Social (ERACIS) (JUNTA DE ANDALUcíA, 2020) como zonas de actuación prioritaria.

Andalucía históricamente es una de las comunidades donde existe el mayor índice de pobreza en el territorio nacional, siendo en el año 2019, la región con el índice más alto después de Extremadura y las dos ciudades autónomas (INE, 2020), y se ha conformado como una de las regiones especializadas en el desarrollo de planes y programas de lucha contra la pobreza y desigualdad urbana como viene haciendo desde finales de los años 80. A pesar del esfuerzo por parte de las administraciones competentes de diseñar e implementar este tipo de estrategias de carácter integral, el territorio andaluz sigue

\begin{tabular}{lccc}
\hline PROVINCIA & № ZDI & PLIZD & \% Desarrollo PLIZD/ZDI \\
\hline Almería & 11 & 3 & $27 \%$ \\
\hline Cádiz & 18 & 10 & $56 \%$ \\
\hline Córdoba & 8 & 4 & $50 \%$ \\
\hline Granada & 13 & 4 & $31 \%$ \\
\hline Huelva & 9 & 3 & $33 \%$ \\
\hline Jaén & 12 & 4 & $33 \%$ \\
\hline Málaga & 14 & 4 & $29 \%$ \\
\hline Sevilla & 14 & 7 & $50 \%$ \\
\hline Total & 99 & 39 & $39 \%$
\end{tabular}

Leyenda: ZDI: Zonas Desfavorecidas Identificadas; PLIZD: Planes Locales de Intervención en Zonas Desfavorecidas; \% Desarrollo PLIZD/ZDI: relación entre la implementación de PLIZD e identificación de ZDI.

FIG. 10/ Relación entre las ZDI y la elaboración de PLIZD.

Fuente: elaboración propia en base a los datos disponibles en página web de la Junta de Andalucía (consultada en octubre de 2020). 
presentando situaciones crónicas de desigualdad y pobreza urbana que responden a dinámicas subyacentes en el sistema socioeconómico en el que nos encontramos a nivel global, y en las que las herramientas utilizadas hasta el momento, a pesar de su carácter integral y su solidez conceptual, tienen escasa capacidad de intervención, lo que hace que funcionen como instrumentos paliativos. En todo caso, esta falta de capacidad de modificación de las causas de la desigualdad urbana, no es un problema exclusivo de las herramientas utilizadas en Andalucía o de la propia ERACIS, sino que es una de las limitaciones de las políticas públicas enfocadas a la reducción de la desigualdad.

Por otra parte, cabe aclarar desde el punto de vista conceptual, que es una estrategia centrada en zonas desfavorecidas que se diferencian en un matiz clave en relación a lo que se han denominado áreas o barrios vulnerables. El concepto vulnerable engloba no sólo a las zonas desfavorecidas, que son aquellas en las cuales la exclusión y desigualdad ya está presente, sino a todas aquellas zonas que por sus circunstancias y contextos se encuentran en una situación de riesgo, es decir, sería una situación previa a la de desfavorecimiento, en la cual se hace necesario intervenir para que su situación no empeore. La Estrategia prioriza las intervenciones en aquellas zonas donde la existencia de exclusión y desigualdad social es patente y recurrente pero no incluye a todas aquellas zonas que podrían llegar a serlo. El Catálogo de Barrios Vulnerables del Ministerio de Fomento del año 2011 recoge un total de 918 barrios vulnerables en el territorio nacional, de los cuales, 215 pertenecen a la región andaluza, es decir, es la región española con más barrios vulnerables, representando un $23 \%$ del total. La ERACIS, por su parte, define un cuerpo de estudio mucho menor y delimita 99 Zonas desfavorecidas (ZDI), lo que resulta coherente con la identificación únicamente de las zonas que efectivamente se encuentran en situación de desfavorecimiento, tal y como indica la nomenclatura que utiliza para ellas (FIG. 11).

En relación a las dimensiones de la vulnerabilidad establecidas como marco por la metodología de evaluación: sociodemográfica, socioeconómica, residencial, subjetiva, del marco urbano y ambiental, la Estrategia, centra su modelo de indicadores de detección en las tres dimensiones tradicionales de la vulnerabilidad urbana: la sociodemográfica, la socioeconómica y la residencial, destacando la segunda, representando el $50 \%$ del peso de éstos y el otro $50 \%$ repartido entre las dos restantes mencionadas. Es un caso en el que no se detallan indicadores de contexto, esto tiene su explicación ya que la implementación de la estrategia se hace mediante los Planes Locales de Intervención en Zonas Desfavorecidas (PLIZD) a través de los ayuntamientos y las diputaciones, que son los que integran éstos a sus situaciones contextuales

\begin{tabular}{lccc}
\hline PROVINCIA & No ZDI & PLIZD & BBVV (2011) \\
\hline Almería & 11 & 3 & 14 \\
\hline Cádiz & 18 & 10 & 56 \\
\hline Córdoba & 8 & 4 & 19 \\
\hline Granada & 13 & 4 & 12 \\
\hline Huelva & 9 & 3 & 9 \\
\hline Jaén & 12 & 4 & 8 \\
\hline Málaga & 14 & 4 & 54 \\
\hline Sevilla & 14 & 7 & 43 \\
\hline Total & 99 & 39 & $\mathbf{2 1 5}$ \\
\hline
\end{tabular}

Leyenda: ZDI: Zonas Desfavorecidas Identificadas; PLIZD: Planes Locales de Intervención en Zonas Desfavorecidas; BBVV: Barrios Vulnerables (2011). 
específicas. Sin embargo, en los indicadores de seguimiento y evaluación de la propia estrategia introduce una dimensión nueva respecto a la detección, y se trata de la dimensión subjetiva: evalúa el grado de satisfacción de los agentes y residentes que participan en la implementación de la estrategia. Teniendo en cuenta que la herramienta establece su marco normativo internacional entorno a la Agenda 2030 y a los objetivos de desarrollo sostenible, llama la atención qué a la hora de llevar a cabo la detección, no tenga en cuenta las dimensiones: ambiental y de marco urbano que presenta la metodología (HERNÁNDEZ $\&$ al. 2020), aunque cabe interpretar que la intención es que éstas se vean en los diagnósticos de contexto a nivel municipal de los cuales son responsables las entidades locales.

\section{Bibliografía}

Agencia Estatal de Evaluación de Políticas (AEVAL) (2015): Guía práctica para el diseño y la realización de evaluaciones de políticas públicas. Ministerio de Hacienda y Administraciones Públicas.

AlguACIL Gómez, J. (2000): Calidad de vida y modelo de ciudad. Calidad de vida urbana: variedad, Cohesión y medio ambiente. Boletín CF+S, 15. http://habitat.aq.upm.es/boletin/n15/ajalg.html

- \& CAmacho GutiérRez, J. \& Hernández AJA, A. (2014): La vulnerabilidad urbana en España. Identificación y evolución de los barrios vulnerables. Empiria. Revista de metodología de ciencias sociales. Universidad Nacional de Educación a Distancia. DOI: https://doi.org/10.5944/empiria.27.2014.10863

ARIAS GOYTRE, F. (director) (2000): La desigualdad urbana en España. Madrid, Ministerio de Fomento, Centro de Publicaciones.

http://habitat.aq.upm.es/due/

CONSEJERÍA DE IGUALDAD Y PoLítICAS SOCIALES (2016): Orden de 1 de marzo de 2016, por la que se aprueban las bases reguladoras para la concesión de subvenciones, en régimen de concurrencia competitiva, en materia de personas mayores, personas con discapacidad, formación de jóvenes en situación de vulnerabilidad, comunidad gitana, personas migrantes, personas sin hogar, atención en materia de drogodependencias y adicciones, para intervención en zonas con necesidades de transformación social y acción social y voluntariado, en el ámbito de las competencias de la Consejería de Igualdad y Políticas Sociales. Boletín Oficial de la Junta de Andalucía. 02/03/2016.

EgEA FERNÁNDEZ, C.\& al., (2008): Vulnerabilidad del tejido social de los barrios desfavorecidos de Andalucía. Análisis y potencialidades. Centro de Estudios Andaluces. Disponible en: https://www.centrodeestudiosandaluces.es/datos/ factoriaideas/ifo11 08.pdf

HeRnÁNDEZ AJA, A.ষ⿳亠口冋 al. (2015): Atlas de Barrios Vulnerables de España: 12 Ciudades 1991/2001/ 2006. Madrid, España, Instituto Juan de Herrera de la Universidad Politécnica de Madrid. ISBN 978-84-9728-518-6. http://oa.upm.es/34999

- (2018): Barrios vulnerables de las grandes ciudades españolas. 1991/2001/2011. Madrid, España, Instituto Juan de Herrera de la Universidad Politécnica de Madrid. ISBN 978-84-9728-568-1. http://oa.upm.es/51015

- (2020): Informe sobre otros Observatorios de la Vulnerabilidad Urbana y su vinculación con las politicas urbanas de regeneración de barrios en Europa y España. Monografía (Informe Técnico). E.T.S. Arquitectura (UPM), Madrid. http://oa.upm.es/66041/

INE. (2020): Tasa de riesgo de pobreza por comunidades autónomas. Madrid: Instituto Nacional de Estadística.

JUNTA DE ANDALUcía (1989): Decreto 202/1989, de 3 de octubre, por el que se crea el plan de barriadas de actuación preferente. Boletín Oficial de la Junta de Andalucía, 7/10/1989.

https://www.juntadeandalucia.es/boja/1989/79/1

- (2003): Plan Andaluz para la Inclusión Social 2003-2006.

https://www.observatoriodelainfancia.es/ ficherosoia/documentos/452 d Plan-Andaluz-deInclusion-Social-2003-2008.pdf

- (2006): Intervención coordinada de la Junta de Andalucía en Zonas con Necesidades de Transformación Social. Disponible en:

http://www.juntadeandalucia.es/salud/servicios/ contenidos/andaluciaessalud/doc/Intervencion.pdf

- (2013): Ley 9/2016, de 27 de diciembre, de Servicios Sociales de Andalucía. Boletín Oficial de la Junta de Andalucía, 03/05/2013.

- (2016): Decreto-ley 7/2013, de 30 de abril, de medidas extraordinarias y urgentes para la lucha contra la exclusión social en Andalucía. Boletín Oficial de la Junta de Andalucía, 29/12/2016.

- (2018a): Acuerdo de 28 de agosto de 2018, del Consejo de Gobierno, por el que se aprueba la «Estrategia Regional Andaluza para la Cohesión e Inclusión Social. Intervención en zonas desfavorecidas» (ERACIS). Boletín Oficial de la Junta de Andalucía, 05/09/2018.

https://www.juntadeandalucia.es/boja/2018/172/1

- (2018b): Estrategia Regional Andaluza para la Cohesión e Inclusión Social. Intervención en Zonas Desfavorecidas (ERACIS).

https://www.juntadeandalucia.es/export/drupaljda/ Estrategia Regional Cohesion Social-web.pdf

- (2018c): Agenda Urbana de Andalucía. https://www.juntadeandalucia.es/organismos/fomentoinfraestructurasyordenaciondelterritorio/ areas/urbanismo/agenda.html\#: :text=Con $\% 20$ la \% 20 aprobaci $\%$ C 3 \% B 3n \% 20 de $\% 20$ la,desarrollo\%20urbano\%20durante $\% 201$ los $\% 20$ pr\%C3\%B3ximos

- (2020): Decreto 91/2020, de 30 de junio, por el que se regula el Plan Vive en Andalucía, de vivienda, rehabilitación y regeneración urbana de Andalucía 2020-2030. Boletín Oficial de la Junta de Andalucía, 03/07/2020. MinisTERIO DE FOMENTO. (2011): Observatorio de la Vulnerabilidad Urbana. https://www.mitma.gob.es/arquitectura-vivienda-ysuelo/urbanismo-y-politica-de-suelo/observatoriode-la-vulnerabilidad-urbana

MINISTERIO DE FOMENTO (2016): Síntesis Metodológica general del Catálogo de Barrios Vulnerables e 
Indicadores Básicos de Vulnerabilidad Urbana. Ministerio de Fomento e Instituto Juan de Herrera de la Universidad Politécnica de Madrid.

https://portalweb2.fomento.gob.es/BarriosVulnerables

- (2019): Agenda Urbana Española. https://www.aue.gob.es/

MiNISTERIO DE SANIDAD, Servicios Sociales E IGUALDAD (2014): Plan Nacional de Acción para la Inclusión Social del Reino de España 2013-2016. https://www.mscbs.gob.es/ssi/familiasInfancia/inclusionSocial/docs/PlanNacionalAccionInclusions ocial 2013 2016.pdf
OCDE (1998): Integrating Distressed Urban Areas. Final report, Urban Affairs Division, OCDE Paris. ISBN 978-92-64-16062-0.

SuBIRATS, J. (1993): Análisis de políticas públicas y gestión pública. Ekonomiaz. Revista vasca de economía. Núm. 26 Pág. 144-149.

Unión EUROPEA (2007): Carta de Leipzig sobre ciudades europeas sostenibles.

https://www.mitma.gob.es/recursos_mfom/ pdf/91B5958A-585C-4E92-8B1F-C06F5CBC4C4B/111500/LeipzigCharte Es cle139ba4.pdf 